\title{
Performed Observation Result Identifier
}

National Cancer Institute

\section{Source}

National Cancer Institute. Performed Observation Result Identifier. NCI Thesaurus. Code C93939.

The unique symbol that establishes identity of the observation result. 